\title{
Mulheres indígenas, igreja e escravidão na América Portuguesa
}

\author{
JANIRA SODRÉ MIRANDA*
}

RESUMO: Este artigo é uma leitura possível da documentação que registra a presença das mulheres indígenas na América Portuguesa. Estabelece uma crítica das representações de mulheres indígenas nos registros europeus evidenciando as relações hierarquizantes e racializadas na sociedade colonial.Visa também evidenciar o campo e o jogo de forças sociais que opõe mulheres de origem indígena e portuguesa na arena política e que as coloca como instrumentos de organização da vida familiar para estabelecer a ordem social. Demonstra ainda o significado da força de trabalho das mulheres indígenas na produção e reprodução da vida social na América Portuguesa.

PALAVRAS-CHAVE: mulheres indígenas, europeus, colônia.

\section{INTRODUÇÃO}

Este trabalho se propõe a analisar a presença das mulheres indígenas na América Portuguesa, a partir dos escritos produzidos por missionários católicos e protestantes, olhar através dos olhos dos missionários para intuir o lugar social ocupado por elas.

Investigar as mulheres no ambiente escravocrata conduz à percepção de que sua situação era o resultado da confluência de muitos fatores, que se cristalizavam para assinalar-lhes uma determinada posição na sociedade colonial da América Portuguesa.

Os espaços ocupados pelas mulheres indígenas na América Portuguesa tinham relação com sua posição na estrutura tribal dos diferentes grupos indígenas do litoral brasileiro, pertencentes todos praticamente ao grande tronco Tupi-Guarni. Assim como as posições ocupadas por mulheres de origem européia ligavam-se aos espaços sociais tidos como femininos em Portugal. Também haverá marcas das sociedades africanas - de tipo sudanês e banto de onde saiu o grosso do tráfico negreiro - na presença das mulheres negras na colônia.

Essas heranças anteriores foram, porém cruzadas e reorganizadas no quadro de uma sociedade patriarcal, organizada sob o padrão misógino europeu, em que os homens brancos detinham posição de força. 
O caráter colonial da presença portuguesa no Brasil do século XVI se impõe de modo particular sobre as mulheres, sobretudo a indígena a mais afetada de todas, neste início - condicionando também as mulheres africanas e as portuguesas.

Acrescente-se a isto o avassalador caráter escravista que adquire esta sociedade desde o momento em que se decidiu o seu povoamento e exploração efetivos, por volta de 1530, para completar o quadro em que irá se desenhar a participação das mulheres nesta sociedade.

As mulheres indígenas irão até os homens pelos caminhos da escravização e isto deixará profundas marcas no relacionamento entre homens e mulheres e na posição destas dentro da sociedade.

É sob a luz desta tríplice dimensão: colonial, escravista e de gênero, que iremos analisar a presença das mulheres na América Portuguesa. A Igreja articula-se, neste contexto, como a instituição que detém um quase monopólio ideológico e um efetivo monopólio religioso na organização desta nova sociedade que se pretende portuguesa e cristã ao mesmo tempo.

Ela esforça-se por regulamentar a vida das pessoas pela orientação ética, pela catequese, pela educação cristã, pelo ritmo semanal recortado pelo domingo e pelo calendário anual marcado pelo ciclo litúrgico do Advento, Natal, Epifania, Quaresma, Páscoa, Pentecostes e pelo ciclo santorial das festas dos padroeiros, dos diferentes apóstolos, mártires, confessores, virgens e doutores e - sobretudo - pelas de Nossa Senhora.

A Igreja faz-se ainda presente no cotidiano das pessoas, com o batismo, a crisma, a eucaristia, o casamento, a extrema unção, os funerais, a penitência e os demais gestos que acompanham os momentos-chave da vida, do nascimento à constituição da família, da reconciliação à morte, da reza doméstica às celebrações comunitárias.

E, por último, mas não menos importante, a Igreja exerce severa vigilância e controle através da observância doutrinal e de costumes pela confissão, pelo sermão e pelas devassas da inquisição.

Sua ação em relação às mulheres se faz particularmente ativa em todo o campo da organização da família nas condições dadas na sociedade colonial. A Igreja irá desdobrar-se em iniciativas e medidas para assegurar o estabelecimento da sociedade familiar nos 
moldes vigentes na organização familiar patriarcal européia. Sem grande sucesso, é preciso reconhecer. Como tem sido sobejamente demonstrado na historiografia mais recente da sociedade colonial (Araújo, 1997).

Uma palavra ainda deve ser dita a respeito das fontes utilizadas. Elas provêm, em sua maior parte, de documentos jesuíticos, capuchinhos e franciscanos, além de relatos, crônicas, leis e correspondência oficial, sobretudo para os século XVI e XVII no que tange às mulheres indígenas.

Para a escravidão negra há sermões, estudos, recenseamentos pastorais e a legislação civil e eclesiástica que se estende até 1888, ano da abolição da escravatura. Para os dois primeiros séculos toda esta literatura consultada é exclusivamente produzida por homens. E não apenas isto, pois quem informa é o homem na posição de colonizador e, para as fontes eclesiásticas, o homem investido da condição de religioso ou de sacerdote e por tanto celibatário, pelo menos em princípio.

Nesta literatura missionária, as mulheres são representadas como símbolos de perigo e ameaça à castidade do religioso. Tudo isto marca os limites e as lacunas do tipo de fone disponível para o nosso tema. Nosso estudo se circunscreverá às mulheres indígenas, e só incidentalmente, trataremos da mulher branca e livre dentro do contexto colonial brasileiro.

\section{AS MULHERES INDÍGENAS EM UMA SOCIEDADE ESCRAVOCRATA}

\subsection{AS MULHERES INDÍGENAS NA REPRESENTAÇÃO DO EUROPEU}

Há um relato interessante do primeiro contato entre os portugueses e a população da costa do Brasil, na carta que escreveu Pero Vaz de Caminha, o escrivão da armada de Cabral, ao Rei de Portugal, dando-lhe notícia da "achada desta vossa terra”. (Lisboa, 1976: 284).

O contato visual que se estabelece entre as naus que se aproximam e os batéis lançados em direção à terra é com “homens que discorriam pela praia”, sendo a atenção atraída pela diferença de cor e ausência de vestuário: “(...) quando o batel chegou à boca do 
rio, já eram ali dezoito ou vinte homens pardos, todos nus, sem coisa alguma que lhes cobrisse suas vergonhas”. ( Lisboa, 1976: 285).

A admiração nasce não apenas da observação da nudez, mas da naturalidade com que passeiam os seus corpos diante do olhar alheio: “A feição deles é serem pardos, tirando a vermelhos, de bons rostos, bons narizes, bem feitos. Andam nus sem nenhuma cobertura, pouco se lhes dá de cobrir ou deixar à mostra suas vergonhas; e acerca disto vivem em tanta inocência como em mostrar o rosto” (Lisboa, 1976: 286).

Só ao terceiro dia aparecem as primeiras mulheres: “Também andavam no maio deles três ou quatro moças de gentil parecer, com cabelos muito pretos que lhes flutuavam pelas espáduas” ( Lisboa, 1976: 287).

No dia em que celebraram solene missa na praia assistida por mais de 160 indígenas, apenas uma mulher estava presente:

Entre todos estes que hoje vieram, não veio mais do que uma mulher moça, veio mais do que uma mulher moça, que assistiu à missa toda. Deram-lhe um pano com que se cobrisse, e puseram-lhe derredor do corpo, porém ela ao sentar-se não fazia memória de o muito estender para cobrir-se; assim senhor, que a inocência desta gente é tal que a de Adão não seria mais, quanto à vergonha (Lisboa, 1976: 294).

É interessante notar que dentre os 160 indígenas desnudos, a preocupação é cobrir a única mulher presente. Esta preocupação pela nudez feminina perpassa todos os textos para o período colonial, sejam eles de cunho eclesiástico ou puramente civil, com se vê no Diretório Pombalino de 1757: o artigo $15^{\circ}$ ordena que se desterre de entre as populações indígenas da Amazônia a desnudez, “... não consentindo de modo algum, que andem nus, especialmente as mulheres, com escândalo da razão e horror da mesma honestidade” (Beozzo, 1983: 136).

O olhar masculino, europeu pousado sobre o corpo desnudo das mulheres indígenas estará eivado de conceitos culturais centrados no controle e ocultamento do corpo, considerado como ocasião de pecado, de modo particular os corpos das mulheres.

Sobre a presença das mulheres entre os grupos que estiveram em contato mais direto com os portugueses, assinalam os cronistas a divisao do trabalho por sexo, cabendo à mulher o trabalho agrícola, depois de realizada a derrubada do mato pelo homem (Salvador, 1975: 81). 
A poligamia chamou a atenção, mas o europeu registra apenas a masculina, objeta que percebia proibição na poligamia feminina (d'Abeville, 1975: 222). Assim como o conceito de incesto, bastante amplo na sociedade européia, levará os missionários a registrarem os graus parentais que eram aceitos para casamento entre os povos indígenas (Salvador, 1975: 82).

Os mecanismos de ordenamento cultural das sociedades indígenas são anotados com bastante interesse pelo europeu que descreve o casamento e sua ruptura (d'Abeville, 1975: 223); a presença das mulheres na divisão sexual do trabalho, a elas cabendo o trabalho agrícola, os adornos, a educação das meninas (Salvador, 1975: 82); o resguardo masculino pós parto (Salvador, 1975, 81); o afeto das mães por seus filhos (d’Abeville, 1975: 224).

As mulheres que arcavam na sociedade indígena com boa parte do trabalho, tinham ainda função importante no preparo das festas rituais, a começar do cauim, fabricado tanto da mandioca como do milho que deviam mascar, antes de cozê-lo em grandes potes.

O cuidado dos prisioneiros, a serem eventualmente mortos na festa, ficava por conta das mulheres. O intuito da entrega de uma mulher ao prisioneiro, normalmente a mais formosa que há na casa, é para que tenha o cuidado de “o regalar e lhe dar de comer até que engorde e esteja pronto para o poderem comer” (Salvador, 1975: 86).Não era raro afeiçoarse a moça prisioneira ou mesmo ter um filho deste:

E é tão cruel este gentio com os seus cativos que não só os matam a eles, mas, se acontece a algum haver filho da moça que lhe deram por mulher, a obrigam que o entregue a um parente mais chegado, para que o mate quase com as mesmas cerimônias, e a mãe é a primeira que lhe come da carne; posto que algumas, pelo amor que lhes têm, os escondem, e às vezes soltam também os presos e se vão com eles, pera suas terras ou pera outras (d’Abeville, 1975: 87).

O tema da crueldade antropofágica das mulheres indígenas irá marcar os escritos europeus como ápice do olhar enviesado sobre os povos ameríndios e, particularmente, sobre as mulheres indígenas (Raminelli, 1997).

Dentre os costumes indígenas alguns serão sistematicamente combatidos pelos missionários, três deles foram considerados particularmente graves: a nudez, a poligamia e a antropofagia. 
Os três diziam respeito tanto ao homem como à mulher, pois faziam parte da sociedade indígena como um todo. Os dois primeiros adquiriam especial conotação no caso da mulher, como já vimos no caso da nudez, onde se problematizava particularmente a nudez feminina.

Também o combate à poligamia atingia de modo particular a mulher. Embora fosse o homem quem oferecesse maior resistência em deixar suas muitas mulheres para poder receber o batismo, pouco se cuidava da situação em eu ficava relegada a mulher, por vezes carregada de filhos, eventualmente de mais idade e que perdia assim seu marido, obrigado a uma escolha penosa e fora das tradições de sua cultura e sociedade. A ele, entretanto, era dada uma escolha ainda que dolorosa e penosa, à mulher, não.

Um último costume indígena pareceu particularmente desconcertante aos europeus e sobretudo aos missionários: o ritual da hospitalidade indígena. Este costume mereceu o título com que Charles Wagley estuda o mundo dos Tapirapé, do norte do Matogrosso: "Welcome of tears”, "Boas-vindas de lágrimas".

A acolhida ao hóspede e ao estrangeiro é toda ela um ritual feminino, no qual os anfitriões choram como sinal de cortesia para com os hóspedes. Quanto ao visitante, “cabelhe fazer o mesmo por cortesia, isto é, pôr as mãos sobre o rosto e chorar, ou pelo menos fingir" (d'Abeville, 1975: 227). A esta acolhida com o oferecimento da rede e da comida, pode seguir-se a oferta de uma mulher para ficar com o hóspede, do mesmo modo que é oferecida ao prisioneiro de guerra.

A Nóbrega e Anchieta, na sua jornada em Iperoig para a pacificação dos Tamoio, foram-lhes oferecidas mulheres na aldeia de Principal Pindobuçu, que os abrigava (Vasconcelos, 1977: 89)

Japi-Açu, o chefe Tupinambá que recebe os franceses no Maranhão, respondendo ao discurso que lhe dirigiu o Pe. Yves d’Évreux, responsável pela missão capuchinha, exprime-lhe sua estranheza pelo modo de agir dos missionários ao rejeitarem as mulheres a eles oferecidas (d'Abeville, 1975, 63)

A oferta das mulheres fazia parte, no mundo indígena, de uma estratégia de alianças. Em vez de dar a mulher, na realidade a família e a tribo conquistavam mais um membro masculino, pois é o homem que passa a residir na casa do pai de sua mulher, passando a servi-la com os frutos da caça e da pesca e também ao sogro e à sua parentela. 
Este sentido mais profundo escapava ao missionário que via aí apenas uma questão de falta de moral, de ofensa ao pudor: "Aliás é coisa muito desonesta prostituirdes assim vossas filhas e elas se entregarem a qualquer um como fazem" (d'Abeville, 1975: 64). A dimensão ética de uma sociedade baseada na reciprocidade de bens, de dons e de entrega de si , como se caracterizavam as sociedades indígenas, escapava aos europeus.

\subsection{AS MULHERES INDÍGENAS NA COLÔNIA}

Na carta de doação das capitanias hereditárias, recebiam os donatários uma série de privilégios entre os quais avultava o de cativar gentios para o seu serviço e o de seus navios e ainda mandar vendê-los em Lisboa (Varnhagen, 7 ed.: 151) Na realidade, o plantio de cana requeria um duplo movimento, o de ocupação da terra, expulsando os grupos indígenas aí presentes e a escravização em larga escala da mão-de-obra, trazendo de volta os índios para os trabalhos das roças de mantimento, do plantio da cana e da fabricação do açúcar nos engenhos.

Isto colocava as aldeias indígenas em contínuo sobressalto, em continuada guerra ou retirada para o sertão distante, disputando rios e territórios a outros grupos. A escravização indiscriminada provoca a desorganização da economia indígena, de sua vida social e política além de extrema mortandade.

Uma inversão quanto aos papéis tradicionalmente executados se opera quando os homens são lançados no trabalho agrícola, tarefa social das mulheres e estas são desviadas pra o serviço doméstico nas casas dos colonizadores, tornando-se suas escravas e sendo submetidas aos seus caprichos sexuais.

\section{3. ÍNDIA, ESCRAVA E MÃE DOS FILHOS DO SENHOR}

A política de invasão de terras e de escravização forçada suscitou crescente e desesperada oposição das tribos do litoral colocando os portugueses na defensiva a tal ponto de Luís de Góis escrever em 1548 a El-Rei, pedindo que viesse em socorro da capitania, “tendo piedade das muitas almas cristãs que só nesta Capitania (de são Vicente) 
entre homens, mulheres e meninos, havia mais de 600 almas e de escravaria, mais de 3.000, seis engenhos e muitas fazendas” (Camargo, 1952, tomo 1: 55)

Não deixa de ser significativo que 14 anos depois de instaladas as capitanias hereditárias e de criados os primeiros engenhos de açúcar no litoral vicentino a escravaria era do gentio da terra.

Parte integrante da violência da escravidão era voltada diretamente para as mulheres. Basta o exemplo da expedição colonizadora de Martim. Afonso que trouxe 300 homens, mas não mulheres.

Como colonizar e povoar sem mulheres? Disto resulta a caça às mulheres indígenas, arrancadas à força de suas aldeias, de seus maridos e filhos para o mundo do colono europeu, dando início à população mameluca que tanto marcou os primórdios da colônia vicentina, da vila de santo André da Borda do campo e, depois, da aldeia de São Paulo de Piratininga.

Um quadro dessa nova situação das mulheres indígenas transferidas para a esfera do projeto colonial, como escrava doméstica, como companheira forçada e reprodutora, surge em todos os documentos.

Na Carta de Pero Borges a D. João III, de 7 de fevereiro de 1550, diz ele: “Há nesta terra casados lá no Reino, quais há muitos dias que andam cá, e não granjeiam - muitos deles ou os mais fazendas, se não, estão emancebados com um par ao menos, cada de gentias. Fazem pior vida que os mesmos gentios.” (Mendonça, 1972: 55).

Se na situação anterior das mulheres indígenas, muitos de seus costumes eram combatidos pelos missionários, na nova situação será combatida menos sua situação de escrava do que o regime de mancebia em que viviam com elas os colonos portugueses.

As cartas dos primeiros jesuítas estão povoadas de referências ao duplo mal que corroía a sociedade colonial: de um lado os "cativeiros injustos” e de outro a situação de mancebia em que viviam os colonos. 


\section{AS MULHERES INDÍGENAS E A REPRODUÇÃO DA VIDA}

$\mathrm{Na}$ sociedade colonial elas ingressam o mais das vezes já sob o signo da escravização e como reprodutora forçada da ordem colonial pois não ascendem ao estado de esposas, e seus filhos não vão engrossar as fileiras do seu povo e sim o partido do pai.

Os mamelucos, filhos de portugueses com índias, foram os instrumentos maiores da opressão que se abate a partir de São Paulo sobre os povos indígenas do Guairá, do Italin e do Tape, onde se agrupava o grosso das missões jesuíticas junto aos Guarani.

Conhecimentos do mundo indígena, pela herança materna, manejando a língua e sabedores dos costumes, mas ao mesmo tempo aliados da dominação portuguesa, eles representam uma temível arma na resistência que podem opor os povos indígenas ao avanço de entradas e bandeiras e à dominação portuguesa.

Para as índias amancebadas, duas ou mais em cada casa de portugueses, armam os jesuítas sua estratégia de moralização. Começam pela denúncia, inclusive pública, do escândalo. Negam a absolvição sacramental aos que assim viviam, afrontando inclusive a posição de outros clérigos coniventes com a situação, ou vivendo em condições semelhantes. Passam em seguida para medidas práticas como podemos ver da abundância sobre o assunto.

As medidas práticas constituem em que viessem honrados, já casados, acompanhados de suas famílias; que se devolvessem a Portugal os homens casados cujas esposas lá estavam e que se haviam amancebado, ou então que se lhes fizesse vir as esposas; que se mandassem órfãs e outras mulheres para os homens daqui e finalmente que se tentasse o casamento destes homens com as índias com as quais já conviviam.

Todas as outras medidas, exceto a última, tinham alcance limitado na situação vigente no Brasil, onde a maioria havia constituído familiares, de fato senão de direito, com mulheres indígenas forras ou escravas.

Contra esta solução levantavam-se vários obstáculos; os homens viviam com mais de uma mulher casa adentro e, mesmo tendo filhos, consideravam infamante casar-se com uma mulher índigena, ainda mais se fosse escrava. Trataremos, no final, do empecilho maior que nascia da estrutura escravista da sociedade. 
O concubinato de homens braços com mulheres indígenas está sobejamente documentado (Leite, 1975, tomo 1: 438), homens pobres que não tinham outra saída acabam casando com as mulheres índias, mas outros se recusavam considerando isto infâmia: "Os mais aqui tinhão índias de muyto tempo, de que tinhão por grande infâmia casarem com ellas” (Leite, 1975: 285).

Aliás, esta idéia de infâmia do sangue estava de tal modo arraigada nos costumes e mesmo na legislação, inabilitando as pessoas para cargos e carreiras civis e eclesiásticas, que só quando a política da Metrópole se tornou francamente incorporadora do espaço amazônico, é que ela abriu mão desta preservação da pureza racial, incentivando então a mestiçagem na bacia amazônica.

A nova política aparece política aparece no alvará Pombalino de 4 de abril de 1755:

Em ordem a promover os casamentos e aliança entre brancos e índios, há el-rei por bem que os vassalos naturais da Europa ou da América, que os contraiam, não fiquem por isso com infâmia alguma, antes muito hábeis para os cargos lugares onde residirem... (Lisboa, 1976: 536).

O diretório Pombalino para as povoações de índios do Maranhão e Pará de 1757, dedica toda sua última parte à política de povoamento e miscigenação (do número 87 a 91), ordenando aos Diretores de aldeias indígenas que por todos os meios ao seu alcance promovam o casamento entre índios e brancos (Beozzo, 1983: 166).

A decantada miscigenação racial da colonização portuguesa deu-se, na prática, quando não havia outro remédio, os homens ajuntando-se então com mulheres indígenas, na falta de mulheres portuguesas, mas recusando-se a casar-se com as mesmas. Deu-se ainda quando razões de Estado impediam os governantes a incentivar a destribalização dos grupos indígenas forçando uma política de aportuguesamento da população.

Basta aduzir um exemplo para se verificar os limites bem claros do apregoado liberalismo de Pombal e a punição violenta do Estado quando o casamento se dá, não entre o branco e uma índia, mas entre um índio e uma negra:

O Vice-rei do Brasil manda dar baixa do posto de capitão-mór a um índio porque, sem atenção às distintas mercês com que pelo alvará antecendente el-rei os havia honrado, se mostrara de tão baixos sentimentos que casou com uma preta, manchando (sic) seu sangue com esta aliança e tornando-se indigno de exercer o referido posto (Lisboa, 1976: 536). 


\subsection{MULHERES, ESCRAVIDÃo E CASAMENTO}

Mas a grande questão de todo o problema matrimonial no Brasil ligava-se, em última instância, ao caráter escravista da sociedade. Estando todo o sistema produtivo assentado sobre a escravidão, os seus efeitos se espraiavam para as outras esferas da sociedade, invadindo as relações familiares, a vida religiosa, as ordenações jurídicas no campo civil e eclesiástico.

O problema aflora claramente nas objeções que levantam os homens amancebados para se casarem com suas índias, escravas e concubinas ao mesmo tempo. Além do pretexto de infâmia, a real razão residia noutro lugar, como confessavam abertamente aos missionários; temendo que ao casarem-se com suas escravas, estas se tornassem forras e livres (Leite, 1975: 293).

De fato, escrevendo ao Rei, vai Nóbrega irá pedir que passe provisão esclarecendo que o casamento da escrava com o senhor ou dos escravos entre si, não desfaz o jugo da escravidão (Leite, 1975: 293)

Em última instância a presença da mulher na América Portuguesa está condicionada pelo caráter colonial de sua sociedade, profundamente marcada pela mentalidade escravista, mas também marcada pela crônica escassez de mulheres brancas.

O que é intocável neste mundo é a escravidão, cujo laço não deve desmanchar-se nem ao nível das relações mais intimas que presidem o encontro entre o homem e a mulher na entrega amorosa. Mantendo a esposa na condição de escrava, o marido faz dele apenas a doméstica para cuidar da casa, para cozinhar, lavar-lhe a roupa e satisfazê-lo sexualmente.

O receio que tinham os senhores de que casando-se com suas escravas estas ficassem automaticamente livres, provinha de uma intuição certa de que verdadeiras relações de esposo para esposa não podiam conviver com a assimetria, a despersonalização e a subordinação implicadas na escravidão.

Estavam eles preocupados em estabelecer formalmente um casamento religioso que salvaguardasse a moralidade dos costumes, mas inteiramente esvaziado de outros conteúdos ensinados pela igreja em torno do sacramento. O matrimônio cristão, instituindo a aliança entre os cônjuges e mantendo ao mesmo tempo a escravidão só podia ser uma contrafação da doutrina crista sobre o sacramento. 
De outro lado, os homens que tinham a intuição de que o casamento não podia ir de par com a manutenção da companheira na escravidão, estimavam melhor a propriedade da escrava do que a conquista de uma esposa.

Neste sentido a escravidão corrompe não o escravo, esvaziado de sua humanidade e dos seus direitos de pessoa, mas corrompe igualmente a humanidade do senhor incapaz já de seguir os ditames da razão e do afeto.

Vale para aqui a fina observação de Gaspar Barléu, cronista da ocupação holandesa no Brasil, ao comentar as funções da religião para a empresa colonial:

Para firmarmos o poder, sem dúvida, valemo-nos também das opiniões religiosas. Cada qual toma a que escolheu como instrumento idôneo para procurar a segurança em beneficio não só da salvação dos homens, mas também da dominação (Barléu, 1974: 71).

Ficavam ainda para os jesuítas duas outras preocupações: o que fazer das muitas mulheres índias que deviam as casas de seus amos ao legitimarem estes suas uniões com uma única delas e como regularizar as situações matrimoniais dos escravos indígenas em mãos de cristãos?

Para o primeiro problema, a saída foi organizar uma casa para recolher as mulheres:”Damos ordem a que se faça huma casa pera recolher todas as moças e molheres do gentio da terra que dá muitos annos que viven entre os chrstaos, e sam christãs e tem filhos dos homeins branquos;” (Leite, 1975: 292)

Para Nóbrega, estas mulheres deste primeiro Recolhimento de Olinda colocados sob a direção de Maria Rosa, uma índia forra, deviam levar adiante um trabalho de missão e catequese (Leite, 1975: 286-287).

Assim pois no Brasil, o primeiro recolhimento de mulheres, semente para a vida religiosa feminina no futuro, fez-se com mulheres indígenas arrancadas do concubinado e destinadas a serem as primeiras catequistas e missionárias de nossa historia.

Com a oposição levantada à vida religiosa feminina, nada de comparável ao colégio de órfãos de Bahia, fundado por Nóbrega logo depois da chegada dos jesuítas ao Brasil, ou ao colégio de São Paulo, para os meninos brasis que aí encontraram sua primeira escola de ler e escrever, floresceu para a educação das mulheres no Brasil colonial. 


\subsection{AS MULHERES NOS ALDEAMENTOS}

Qual a situação das mulheres indígenas nos aldeamentos mais organizados da região amazônica, quando aí prevaleceu a administração do temporal e do espiritual confiada aos missionários, a partir do Regimento da Missões de 1655? A política dos aldeamentos era de resguardar ao máximo as mulheres, dificultando a sua cessão como mão-de-obra, fora da aldeia.

O regulamento interno das aldeias de missão preparado pelo Pe. Vieira nos dá uma idéia aproximada da situação das mulheres nestes aldeamentos.

Meninos e meninas participavam da catequese diária pela manhã e pela tarde e também da escola.

Quanto ao casamento, desaconselhavam os padres que acontecesse entre índios de uma aldeia com índia de outra. Quando não fosse possível impedir sem ferir a liberdade do matrimônio, devia o padre declarar à contraente que ficava obrigada a seguir a seu marido, “e ir viver à sua Aldeia todas as vezes que ele quiser; e este direito se declare em todas as Aldeias, e se intime aos Principais, para que o tenham entendido e aceitado” (Beozzo, 1983: 189- 208).

Esta imposição dos padres contraria o costume de que ao casar-se era o moço que ingressava no clã da moça, indo morar na casa do sogro, até o tempo de construir sua própria cabana.

O Regulamento contemplava também a espinhosa questão do casamento de índios livres com escravas:

Nos casamentos de livres com escravas (em que são ainda maiores inconvenientes) se tenha a mesma vigilância, se guarde a concordata, que sobre esta matéria se tem feito com o Ordinário, não recebendo, nem consentindo que se receba índio algum das Aldeias sem primeiro ser examinado e desenganado pelo Superior da Colônia, para evitar os dolos, em que debaixo do nome de Matrimonio vêm estes casamentos a ser uma das espécies de cativar, que neste Estado se usa” (Beozzo, 1983: 189-208).

A precaução de Vieira não era excessiva pois os Regimentos posteriores são obrigados a retornar à questão, visto que nenhum meio era deixavam de lançar pelos colonizadores, para se aumentar o número de escravos. Os senhores não deixavam de lançar mão do expediente de atrair índios livres para se casarem com suas escravas, ficando 
eles mesmos, através da ligação com a escrava, em situação de cativeiro. Assim, longe de o casamento tornar forros os que se casavam, vinha a constituir-se caminho a mais para escravizar pessoas.

Também na melindrosa questão da repartição dos índios de serviço que os aldeamentos deviam fornecer para a coleta do cravo e do cacau e para as roças e afazeres domésticos dos colonos, coloca Vieira um particular cuidado, evitando que as mulheres precisem deixar a aldeia e regulamentando as exceções (Beozzo, 1983: 205).

Concluímos este comentário acerca de relatos, leis e normas sobre a mulher indígena na colônia, com um texto que associa no preparo da farinha, alimento básico de toda a área amazônica e prescreve a cessão de armas de leite para os colonos brancos.

É das índias farinheiras e amas de leite que se ocupa o Regimento das Missões de 1686. Depois de proibir a saída de crianças e mulheres da aldeia para o serviço dos brancos, observa:

(...) mas porque na ocasião em que se recolhem os frutos que se lançarão à terra, são necessários aos moradores algumas índias, que se chamão farinheyras, e também necessitão os mesmos moradores de índias para lhe criarem seus filhos, e he razão que humas e outras se occupem neste serviço sem perigo de sua honestidade encarrega muyto aos Reytores dos Collegios, e Prelados das Missoens, que elles no tempo conveniente, e necessário, fassão repartir e com effeito dern a taes índias farinheyras e de leyte a aqullas pessoas que as houverem de tratar bem no espiritual e no temporal arbitrando-lhe sellario que devem vencer ao tempo deste serviço, para que consigão o justo interece delle, e não possão exceder o dito tempo, sempre as taes pessoas recorrão aos ditos Padres, a que elles hajão por justificada a mayor dilatação que se lhes pedir (...) ( Beozzo, 1983: 136).

As mulheres indígenas emergem neste registro como sujeitos históricos em dois aspectos centrais para a reprodução da sociedade colonial na região amazônica: o cuidado maternal, pelo aleitamento, com os filhos dos colonos e a reprodução da vida social, a partir da produção do alimento básico para a população da região.

\section{NOTAS}

* Janira Sodré Miranda é mestre em Ciências da Religião e aluna especial do Programa de Pósgraduação em História da UnB. Membro da RIEF (Rede Interdisciplinar de Estudos Feministas do Centro-Oeste) e Membro do CEHILA (Centro de Estudos Históricos da Igreja na América Latina). 


\section{REFERÊNCIAS BIBLIOGRÁFICAS}

\section{DOCUMENTOS IMPRESSOS}

Carta de Pero Vaz de Caminha, apud João Francisco, Lisboa, Crônica do Brasil Colonial Apontamentos para a história do Maranhão, Vozes, Petrópolis, INL. Brasília, 1976.

Serafem Leite, Cartas dos Primeiros Jesuítas do Brasil, Tomo I.

Vicente do Salvador, Historia Do Brasil (1500 - 1627), Melhoramentos, São Paulo, INL, Brasília, 1975.

Claude d'Abeville, História da Missão dos Padres Capuchinhos na Ilha do Maranhão e terras circunvizinhas, Itatiaia, Belo Horizonte, EDUSP, São Paulo, 1975.

Francisco Adolfo de Varnhagen, História Geral do Brasil, tomos I e II, Melhoramentos, São Paulo, $7^{\mathrm{a}} \mathrm{ed}$.

Paulo Florêncio da Silveira Camargo, Historia da Igreja de São Paulo, Ed. Graf. J. Magalhães, São Paulo, 1952, tomo I.

Marcos Carneiro de Mendonça, Raízes da Formação Administrativa do Brasil, IHGB - Conselho Federal de Cultura, 1972, tomo I.

Serafim Leite, Historia da Companhia de Jesus no Brasil, Livraria Portugalia, Lisboa, Civilização Brasileira, Rio de Janeiro, 1938, tomo II.

Gaspar Barléu, História dos feitos recentemente praticados durante oito anos no Brasil e noutras partes sob o governo do ilustríssimo João Mauricio, Conde de Nassau, Itatiaia, Belo Horizonte, EDUSP, São Paulo, 1974.

\section{Publicações}

ALGRANTI, Leite Mezan. Honrados e devotas: mulheres da colônia. Brasília: EdUNB/ Rio de Janeiro: Jose Olimpio. 1993.

ALMEIDA, Rita Heloísa de. O diretórios dos índios:um projeto de civilização no Brasil do século XVIII. Brasília: Ed. UnB. 1997.

ARAÚJO, Emanuel. O teatro dos vícios: transgressão e transigência na sociedade urbana colonial. Brasília: Ed. UnB. Rio de Janeiro: Ed. José Olímpio. 1997.

BAETA NEVES, Luiz Filipe. O combate dos soldados de Cristo na terra dos papagaios: colonialismo me repressão cultural. Rio de Janeiro: Fonseca. 1978.

BEOZZO, José Oscar. Leis e Regimentos das Missões - Política Indigenista no Brasil. Edição Loyola, 1983.

CERTEAU, Michael de. A invenção do cotidiano. Petrópolis: Vozes, 1994, $2^{\mathrm{a}}$ ed.

FIGUEIREDO, Luciano Raposo de. Barrocos famílias: vida familiar em Minas Gerais no século XVIII. São Paulo: HUCITEC, 1997.

HOLANDA, SERGIO Burarque de . A época colonial: do descobrimento a expansão territorial. Rio de Janeiro: Bertrand Brasil. 1989. $8^{\text {a }}$ ed. - (Historia geral da civilização brasileira;1).

TORRES-LONDONO, Fernando. A outra família: concubinato, igreja e escândalo na colônia. São Paulo: Ed. Loyola. 1999.

MARCILIO, Maria Luiza (Org). A mulher pobre na historia da igreja latino-americano. São Paulo: Paulinas. 1984. 
PERROT, Michelle. Os excudidos da historia: operários, mulheres, prisioneiros. São Paulo: Paz e terra. 1988.

PRIORE, Mary Del (org). Historia das mulheres no Brasil. São Paulo. Contexto. 1997.

PRIORE, Mary Del. Ao sul do corpo: condição feminina, maternidades e mentalidades no Brasil colônia. Rio de Janeiro: Bertrand do Brasil, 1993.

RAMINELLI, Ronald. Eva tupinambá. In: História das mulheres no Brasil. São Paulo: Ed. Contexto.1997.

RAMINELLI, Ronald. Imagens da colonização: a representação do índio de Caminha a Vieira. Rio de Janeiro: Ed. Jorge Zahar, 1996.

SILVA, Maria Beatriz Nizza. Historia da família no Brasil colonial. Rio de Janeiro: Nova Fronteira, 1998.

SOUZA, Laura de Mello e. Historia da vida privada no Brasil. São Paulo: Cia. Das letras. 1997 (Historia da vida privada no Brasil; 1).

VASCONCELOS, Simão de. Crônica da Companhia de Jesus. Vozes, Petrópolis, INL, Brasília, 1977, $3^{\text {a }} \mathrm{ed}$. 